\section{Scientific journal}

\section{PHYSICAL AND MATHEMATICAL EDUCATION}

Has been issued since 2013.

Науковий журнал

ФІЗИКО-МАТЕМАТИЧНА ОСВІТА

Видається з 2013.
ISSN 2413-158X (online)

ISSN 2413-1571 (print)



Легка Л.В. Структура та зміст компетентностей з основ квантової інформатики учнів ліцеїв. Фізикоматематична освіта, 2021. Випуск 5(31). С. 54-59.

Lehka L. Structure and content of competences on the basics of quantum informatics of pupils from lyceums. Physical and Mathematical Education, 2021. Issue 5(31). P. 54-59.

DOI 10.31110/2413-1571-2021-031-5-008

УдК 373.5.016:[004.4+530.145]

л.В. Легка

Криворізький державний педагогічний університет, Україна asp18-lehka@kdpu.edu.ua https://orcid.org/0000-0001-5768-5475

\title{
СТРУКТУРА ТА ЗМІСТ КОМПЕТЕНТНОСТЕЙ З ОСНОВ КВАНТОВОЇ ІНФОРМАТИКИ УЧНІВ ЛІЦЕЇВ
}

\section{АНОТАЦІЯ}

У статті представлені результати експертного опитування щодо визначення складових компетентностей з основ квантової інформатики учнів ліцеїв.

Формулювання проблеми. Стрімкий розвиток та перспективність квантових технологій у світі є очевидними передумовами чергової трансформації змісту навчання інформатики в з3СО України, а також уточнення результатів його опанування - складових інфооммаційно-комунікаційної (цифрової) компетентності. Консорціум QTEdи у травні 2021 року опублікував першу версію Європейської рамки компетентностей у галузі квантових технологій (European Competence Framework for Quantum Technologies), складові якої $\epsilon$ основою для визначення відповідних компетентностей для здобувачів освіти, зокрема повної загальної, а також для впровадження та реалізації освітньо-наукових проєктів квантової галузі.

Матеріали і методи. Для отримання результатів дослідження були застосовані емпіричний метод (опитування у вигляді напіввідкритого анкетування, де поряд із запропонованими варіантами відповідей можна було надати власні змістовні коментарі-рекомендації) та здійснений статистичний аналіз результатів опитування (ранжування для визначення важливості складових компетентностей).

Результати. Проведене експертне опитування, до якого долучилися переважно вчителі та викладачі, надало змогу отримати відповіді й рекомендації щодо остаточного визначення змісту компетентностей з квантової інформатики учнів ліцеїв: компетентності з фізичних основ квантових технологій; компетентності з математичних основ квантової інформатики; компетентності із забезпечувальних технологій; компетентності з апаратного забезпечення квантових комп'ютерів та датчиків; компетентності з квантових обчислень та моделювання; компетентності з квантових датчиків та метрології; компетентності з квантової комунікації; практичні навички та загальних компетентностей.

Висновки. Визначені структура та зміст компетентностей з основ квантової інформатики учнів ліцеїв дали змогу уточнити зміст відповідного факультативного курсу.

ключовІ СловА: квантові технології, квантова інформатика, компетентнісний підхід, компетентності з основ квантової інформатики.

\section{ВСТУП}

Постановка проблеми. Сучасна школа повинна надавати знання, що актуальні не лише для сьогодення, а й на далеку перспективу. Значущими складовими мети освіти $€$ всебічний розвиток людини, їі інтелектуальних та творчих здібностей, формування цінностей і компетентностей, необхідних для ії успішної самореалізації, підвищення освітнього рівня громадян задля забезпечення сталого розвитку України (6). Це зумовлює випереджальний і інноваційний характер освіти та необхідність ії модернізації на основі системного, методично обгрунтованого упровадження основ квантової інформатики в інформатичну освітню галузь.

Аналіз актуальних досліджень. Переконливим свідченням такої необхідності $\epsilon$ спільна робота Національного фонду досліджень та уряду США із «квантової трансформації» шкільної освіти. Зокрема, у 2020 році були визначені 9 ключових концепцій шкільного курсу основ квантової інформатики, серед них квантовий стан, вимірювання у квантовій системі, кубіт, сплутаність, когерентність, квантові комп'ютери, квантова комунікація та квантове панування (3). Реалізація цієї трансформації у рамках National Q-12 Education Partnership спрямована на те, щоб «... упродовж наступного десятиліття співпрацювати із американськими вчителями з метою створення потужного квантового середовища 
навчання, розпочинаючи від надання засобів для розробки практико зорієнтованих навчальних матеріалів і закінчуючи спрямуванням на професії в галузі квантових технологій. ... Разом ми можемо підготувати нову генерацію американських професіоналів, озброєних засобами досягнення успіху в індустрії майбутнього» (2).

За прогнозами учасників саміту «Pioneers of Change» до 2025 року квантові обчислення переростуть своє зародження, і на повну потужність запрацює перше покоління комерційного квантового обладнання для розв'язання реальних задач, зокрема - моделювання складних хімічних реакцій для розробки ліків та речовин із наперед заданими властивостями (1).

У Державному стандарті базової середньої освіти (5) питання квантових технологій не розглядаються через те, що опанування їх елементів (зокрема, початки квантової фізики) передбачено на третьому рівні повної загальної середньої освіти - у профільній середній освіті, що передбачає виконання учнем вимог до результатів навчання, які мали бути визначені державним стандартом профільної середньої освіти, затвердження якого заплановане на 2023 рік. Це зумовлює необхідність уточнення змісту інформаційно-комунікаційної компетентності учнів ліцеїв шляхом уведення до неї компетентностей з основ квантової інформатики.

У рамках європейського проєкту «Quantum Flagship» розробляється рамка компетентностей у галузі квантових технологій (European Competence Framework for Quantum Technologies) (4), що у майбутньому стане розширенням рамки цифрових компетентностей DigComp та стане відправною точкою для планування і структурування різноманітних освітньонаукових проектів з квантових технологій.

Будемо визначати компетентності з основ квантової інформатики учнів ліцеїв як динамічну комбінацію знань, умінь, навичок, способів мислення, поглядів, інших особистих якостей у сфері квантових технологій, що визначає здатність особи успішно провадити подальшу професійну та/або навчальну діяльність із використанням таких технологій. А, згідно Європейської рамки компетентностей у галузі квантових технологій, вони включають у себе групи компетентностей, що охоплюють такі питання: 1) фізичні основи квантових технологій (основні поняття квантової фізики, динаміка кубітів); 2) математичні основи квантової інформатики (основи лінійної алгебри, математика основ квантової фізики, основи статистики квантових вимірювань); 3) забезпечувальні технології (оптичні технології, лабораторні технології, експериментальне керування); 4) апаратне забезпечення квантових комп'ютерів та датчиків (пристрої на основі спіну, нейтральні атоми та іони, нові види кубітів, обладнання для ініціалізації, маніпуляції та зчитування кубітів, використання апаратних платформ для квантових обчислень); 5) квантові обчислення та моделювання (квантові вентилі, квантові мови, засоби та платформи програмування, базові квантові алгоритми, квантова корекція помилок, елементи квантового моделювання); 6) квантові датчики та метрологія (атомні годинники, галузі застосування квантових датчиків); 7) квантова комунікація (квантова криптографія, квантові мережі, інфраструктура та обладнання квантового зв'язку); 8) практичні навички та загальні компетентності (основи класичного програмування, застосування квантових технологій, загальні навички/компетентності).

Мета статті - уточнення складових груп компетентностей (знань та умінь) з основ квантової інформатики учнів ліцеїв за результатами експертного опитування.

\section{МЕТОДИ ДОСЛІДЖЕННЯ}

Для отримання результатів дослідження були застосовані емпіричний метод (опитування у вигляді напіввідкритого анкетування, де поряд із запропонованими варіантами відповідей можна було надати власні змістовні коментарі-рекомендації) та здійснений статистичний аналіз результатів опитування (ранжування для визначення важливості складових компетентності).

\section{РЕЗУЛЬТАТИ}

3 метою виявлення значущості складових Європейської рамки компетентностей у галузі квантових технологій, а також отримання рекомендації щодо змісту навчання шкільного курсу основ квантової інформатики було проведено опитування серед зацікавлених у галузі квантових технологій. В опитуванні взяли участь 36 респондентів, частина з яких суміщають декілька посад - наприклад, викладача ЗВО та співробітника НДІ чи викладача ЗВО й учителя 33СО.

Кожному із респондентів було запропоновано виконати самооцінювання власного рівня компетентності у квантовій інформатиці. Глибокий рівень обізнаності з окремими складовими виявили 11,1\% респондентів, 41,7\% вказали на обізнаність з окремими складовими, а 47,2\% - на наявність початкових уявлень з квантової інформатики. Через складність та міждисциплінарний характер галузі жоден із респондентів не ідентифікував себе як особу, глибоко обізнану з усіма складовими, тому для опрацювання відповідей респондентів було визначено наступні вагові коефіцієнти для кожної з категорій опитаних: 1 - маю початкові уявлення, 2 - обізнаний з окремими складовими, 3 - глибоко обізнаний $з$ окремими складовими, 4 - експерт.

Більшість питань анкети передбачали оцінювання доцільності уведення до змісту навчання різних знань та умінь з основ квантової інформатики за шкалою: -1 - зовсім не важливо, 0-утрудняюсь відповісти, 1 - мало важливо, 2-скоріше важливо, 3 - дуже важливо. Відповіді «утрудняюсь відповісти», що кодувалися значенням 0, передбачалися для учасників опитування, які не в повній мірі могли оцінити окремі компоненти через необізнаність в оцінюваних знаннях чи неволодіння відповідними уміннями.

Оцінка важливості кожної із складових компетентності учнів ліцеїв з основ квантової інформатики обчислювалась за формулою (1):

де:

$$
A_{k m}=\sum_{i=1}^{n} w_{i} a_{i k m}
$$

$n$ - кількість експертів (на кінець опитування $n=36$ );

$i$ - номер експерта $(i=1, \ldots, n)$;

$k$-номер групи компетентностей з основ квантової інформатики $(k=1 \ldots 8)$; 
$m$ - номер складової $k$-тої групи компетентностей з основ квантової інформатики;

$A_{k m}$ - оцінка важливості $m$-тої складової $k$-тої групи компетентностей $\left(A_{k m}=-1 * 4 * n \ldots 3 * 4 * n\right)$;

$w_{i}$ - рівень компетентності $i$-того експерта у квантовій інформатиці $\left(w_{i}=1, \ldots, 4\right)$;

$a_{i k m}$ - оцінка важливості $i$-тим експертом $m$-тої складової $k$-тої групи компетентності.

Визначення найбільш важливих складових виконувалось наступним чином: якщо $A_{k m}$ не менше за порогове значення, відповідна складова відбиралась, інакше - не відбиралась.

Порогове значення $P=120,8$ обчислювалося за формулою (2):

$P=\min \left(A_{k m}\right)+0,45 *\left(\max \left(A_{k m}\right)-\left(\min \left(A_{k m}\right)\right.\right.$,

де: $\min \left(A_{k m}\right)=92 ; \max \left(A_{k m}\right)=156$.

Ураховуючи, що до оцінюваних складових були залучені як знання, так й уміння, у випадку, якщо для відібраного уміння не було відібрано відповідного йому знання, нами було додатково виконано його відбір.

У таблиці 1 наведено відібрані результати опитування та їх статистичного аналізу. У стовпці «Вибір» напроти кожної складової компетентності зазначається «*» - обрана учасниками опитування за умови перевищення показника порогового значення $P$ або «+» - додана автором до переліку як відповідні знання до обраних учасниками опитування умінь.

Таблиця 1.

Оцінювання важливості складових компетентностей з основ квантової інформатики

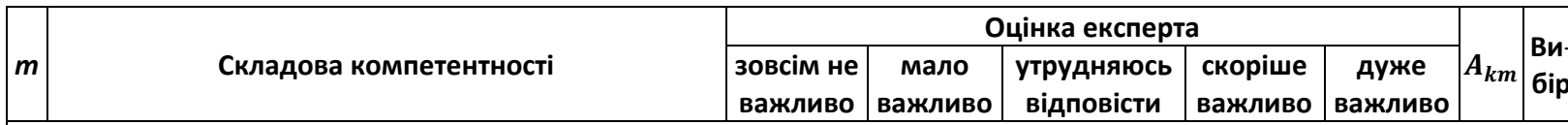

Складові групи компетентностей з фізичних основ квантових технологій ( $k=1, m=1 . .8$ )

1 знання основних понять квантової фізики

3 уміння визначати, чи знаходяться кубіти у

3 пов'язаних (заплутаних) станах

\begin{tabular}{l|l}
7 & уміння подавати кубіт на сфері Блоха \\
\hline
\end{tabular}

\begin{tabular}{l|l}
2 \\
4 \\
4
\end{tabular}

\begin{tabular}{l|l|l|l}
1 \\
5 \\
7
\end{tabular}

\begin{tabular}{|l|l|l|l|}
\hline 13 & 19 & 139 & $*$ \\
\hline 14 & 12 & 115 & + \\
\hline 16 & 7 & 92 & + \\
\hline
\end{tabular}

Складові групи компетентностей з математичних основ квантової інформатики $(k=2, m=1 . .10)$

\begin{tabular}{l|l}
\hline 1 & знання основ теорії комплексних чисел \\
\hline 2
\end{tabular}

2 знання основ лінійної алгебри

3 знання математичних основ квантової фізики 1

4 знання статистичної природи квантових ${ }_{1}$

4 вимірювань

6 уміння подавати вектори (матриці-стовпці, матриці- 1

6 рядки) у бра-кет нотації

7 уміння оперувати із стандартними базисами

8 уміння подавати вектор у обраному базисі

уміння наводити приклади унітарних матриць та

10 виконувати дії з ними

\begin{tabular}{|l|l|}
\hline 3 \\
\hline 4 \\
\hline 1 \\
\hline 4 \\
\hline 4 \\
\hline 2 \\
\hline 3 \\
\hline 3
\end{tabular}

Складові групи компетентностей із забезпечувальних технологій $(k=3, m=1 . .5)$

\begin{tabular}{|l|l|l|l|l|l|l|l|l|}
\hline 1 & знання оптичних технологій & 2 & 1 & 2 & 17 & 14 & 128 & $*$ \\
\hline 2 & знання лабораторних технологій & 2 & 1 & 3 & 15 & 15 & 126 & $*$ \\
\hline 3 & знання експериментального управління & 1 & 1 & 2 & 18 & 14 & 130 & * \\
\hline 4 & уміння розрізняти джерела фотонів & 1 & 2 & 1 & 22 & 10 & 128 * \\
\hline
\end{tabular}

Складові групи компетентностей з апаратного забезпечення квантових комп'ютерів та датчиків $(k=4, m=1 . .8)$

1 знання будови пристроїв на основі спіну (зокрема,

1 напівпровідникових квантових точок)

знання апаратних платформ для квантових

5 обчислень, способів ї інтеграції 3 класичним 2

обладнанням

6 Уміння описувати типові структури квантових ком-

$6 \begin{aligned} & \text { п'ютерів, пояснювати загальні принципи їх роботи } \\ & \text { п' }\end{aligned}$

7 уміння виконувати налаштування віддаленого 1

7 доступу до квантових комп'ютерів

8 Уміння виконувати квантові програми на квантових 1

$8 \begin{aligned} & \text { комп'ютерах } \\ & \text { ком }\end{aligned}$

\begin{tabular}{|l|l|l|l|l|}
\hline 3 & 0 & 28 & 144 & $*$ \\
\hline 2 & 0 & 30 & 156 & $*$ \\
\hline 3 & 0 & 31 & 156 & $*$ \\
\hline 1 & 0 & 30 & 148 & $*$ \\
\hline 2 & 12 & 17 & 134 & $*$ \\
\hline 2 & 14 & 17 & 137 & $*$ \\
\hline 1 & 16 & 14 & 128 & $*$ \\
\hline
\end{tabular}

Складові групи компетентностей з квантових обчислень та моделювання $(k=5, m=1 . .14)$

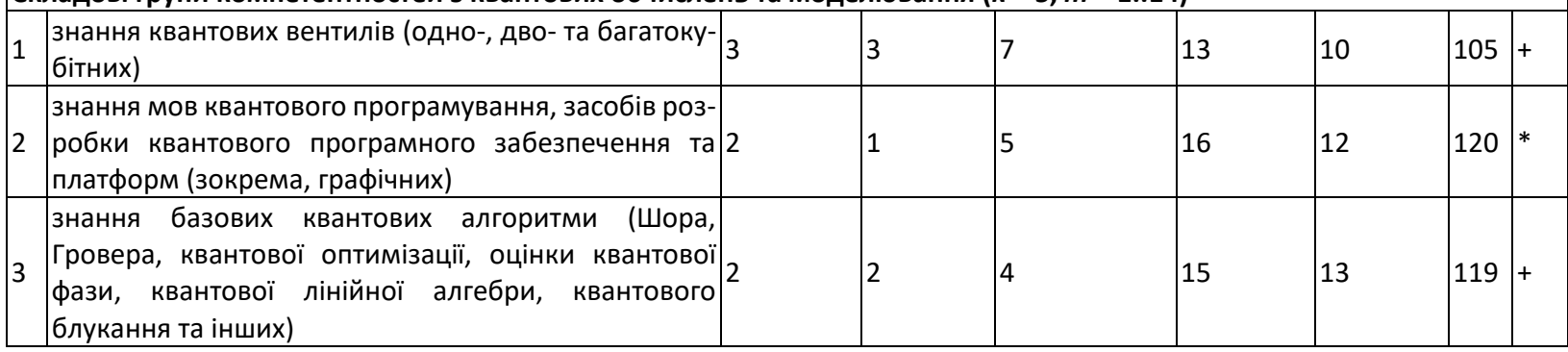


Тема уроку та компетентності, що будуть сформовані/удосконалені

\section{2. Арифметико-логічні основи роботи класичного комп'ютера (1 година)}

Компетентності з математичних основ квантової інформатики: знання основ лінійної алгебри; уміння наводити приклади унітарних матриць та виконувати дії з ними; уміння оперувати із стандартними базисами; уміння подавати вектор у обраному базисі.

\section{3. Кубіт. Квантовий логічний вентиль Паулі X (1 година)}

Компетентності з фізичних основ квантових технологій: уміння подавати кубіт на сфері Блоха.

Компетентності з математичних основ квантової інформатики: знання основ лінійної алгебри; уміння подавати вектори (матриці-стовпці, матриці-рядки) у бра-кет нотації; уміння наводити приклади унітарних матриць та виконувати дії з ними; уміння оперувати із стандартними базисами; уміння подавати вектор у обраному базисі; знання математичних основ квантової фізики; знання статистичної природи квантових вимірювань.

Компетентності з квантових обчислень та моделювання: знання квантових вентилів (одно-, дво- та багатокубітних), уміння розрізняти та застосовувати однокубітні вентилі (перетворення Паулі).

\section{4. Квантові логічні вентилі Паулі Z, Y. Комплексні числа (1 година)}

Компетентності з фізичних основ квантових технологій: уміння подавати кубіт на сфері Блоха.

Компетентності з математичних основ квантової інформатики: знання основ теорії комплексних чисел; знання основ лінійної алгебри; уміння подавати вектори (матриці-стовпці, матриці-рядки) у бра-кет нотації; уміння наводити приклади унітарних матриць та виконувати дії з ними.

Компетентності з квантових обчислень та моделювання: знання квантових вентилів (одно-, дво- та багатокубітних), уміння розрізняти та застосовувати однокубітні вентилі (перетворення Паулі).

\section{5. Квантові логічні вентилі Адамара та контрольованого заперечення. Розв'язання задач (1 година)}

Компетентності з квантових обчислень та моделювання: знання квантових вентилів (одно-, дво- та багатокубітних), уміння розрізняти та застосовувати однокубітні вентилі (перетворення Паулі, вентиль Адамара, фазові зсуви); уміння виконувати операції за допомогою багатокубітних вентилів.

6. Алгоритм квантової телепортації. Реалізація алгоритму квантової телепортації за допомогою графічного середовища (1 година)

Компетентності з фізичних основ квантових технологій: уміння математично описувати квантову телепортацію. Компетентності з апаратного забезпечення квантових комп'ютерів і датчиків: знання апаратних платформ для квантових обчислень, способів їх інтеграції з класичним обладнанням; уміння виконувати налаштування віддаленого доступу до квантових комп'ютерів; уміння виконувати квантові програми на квантових комп'ютерах.

\section{7. Основи програмування (1 година)}

Практичні навички та загальні компетентності: знання основ класичного (неквантового) програмування: мов програмування, алгоритмів, класів складності, криптографії; знання галузей застосування квантових технологій; уміння реалізовувати базові класичні алгоритми (зокрема, криптографічні) мовами програмування.

8. Програмування квантових алгоритмів. Реалізація алгоритму квантової телепортації у середовищі програмування (1 година)

Компетентності з апаратного забезпечення квантових комп'ютерів і датчиків: знання апаратних платформ для квантових обчислень, способів їх інтеграції з класичним обладнанням; уміння виконувати налаштування віддаленого доступу до квантових комп'ютерів; уміння виконувати квантові програми на квантових комп'ютерах.

Компетентності з квантових обчислень та моделювання: знання мов квантового програмування, засобів розробки квантового програмного забезпечення та платформ (зокрема, графічних).

\section{9. Квантові вентилі Тоффолі та Фредкіна (1 година)}

Компетентності з апаратного забезпечення квантових комп'ютерів і датчиків: знання апаратних платформ для квантових обчислень, способів їх інтеграції з класичним обладнанням; уміння виконувати налаштування віддаленого доступу до квантових комп'ютерів; уміння виконувати квантові програми на квантових комп'ютерах.

Компетентності з квантових обчислень та моделювання: знання мов квантового програмування, засобів розробки квантового програмного забезпечення та платформ (зокрема, графічних); уміння виконувати операції за допомогою багатокубітних вентилів (CNOT, вентилі Тоффолі та Фредкіна).

\section{0. Квантова комунікація. Квантова криптографія (1 година)}

Компетентності з квантової комунікації: знання квантової криптографії (квантового розподілу ключа, безпечної автентифікації, цифрових підписів, галузей застосування); знання про квантові мережі (квантовий Інтернет, сенсорні та годинникові мережі); знання інфраструктури та обладнання квантового зв'язку (волоконно-оптичні системи, бездротовий зв'язок, супутникові системи; квантові генератори випадкових чисел; квантова пам'ять, інтерфейси, комутатори; повторювачі, кінцеві вузли); уміння описувати принципи роботи та будову обладнання квантових мереж; уміння наводити приклади застосування квантової криптографії у різних галузях.

Компетентності зі забезпечувальних технологій: знання оптичних технологій; знання лабораторних технологій; знання експериментального управління; уміння розрізняти джерела фотонів.

11. Алгоритм Бернштейна-Вазірані. 12. Алгоритм Дойча-Йожи. 13. Алгоритм Гровера. 14. Алгоритм Шора. 15-16. Бібліотеки квантових алгоритмів (6 годин)

Компетентності з апаратного забезпечення квантових комп'ютерів і датчиків: знання апаратних платформ для квантових обчислень, способів їх інтеграції з класичним обладнанням; уміння виконувати налаштування віддаленого доступу до квантових комп'ютерів; уміння виконувати квантові програми на квантових комп'ютерах.

Компетентності з квантових обчислень та моделювання: знання мов квантового програмування, засобів розробки квантового програмного забезпечення та платформ (зокрема, графічних); знання базових квантових алгоритмів; уміння 


\section{Тема уроку та компетентності, що будуть сформовані/удосконалені}

застосовувати квантові вентилі для запису квантових алгоритмів; здатність послуговуватись мовами та засобами квантового програмування.

\section{7. Підсумковий урок (1 година)}

\section{ВИСНОВКИ ТА ПЕРСПЕКТИВИ ПОДАЛЬШОГО ДОСЛІДЖЕННЯ}

Ґрунтуючись на фундаментальних ідеях компетентнісного підходу у навчанні, а також взявши за основу структуру та зміст Європейської рамки компетентностей у галузі квантових технологій, визначено складові компетентностей з основ квантової інформатики для учнів ліцеїв.

Напрямом подальшого дослідження слід визначити удосконалення методичних матеріалів факультативного курсу «Основи квантової інформатики» для учнів ліцеїв.

Future shocks: 17 technology predictions for 2025. World Economic Forum. URL: https://www.weforum.org/agenda/2020/06/17-predictions-for-our-world-in-2025 (дата звернення: 30.09.2021).

2. Home | National Q-12 Education Partnership. Q2WORK : веб-сайт. URL: https://q12education.org/about (дата звернення: 27.09.2021).

3. Key Concepts for Future QIS Learners 5-20. URL: https://files.webservices.illinois.edu/9156/keyconceptsforfutureqislearners520.pdf (дата звернення: 30.09.2021).

4. Quantum Technology Competence for $\quad$ FTamework 1.0. URL: https://qt.eu/app/uploads/2019/02/Competence_Framework_for_QT_1.0_May2021.pdf (дата звернення: 30.09.2021).

5. Про деякі питання державних стандартів повної загальної середньої освіти : Постанова Кабінету Міністрів України; Стандарт, Вимоги від 30.09.2020 № 898 // База даних «Законодавство України» / Верховна Рада України. URL: https://zakon.rada.gov.ua/go/898-2020-\%D0\%BF (дата звернення: 30.09.2021).

6. Про Національну стратегію розвитку освіти в Україні на період до 2021 року : Указ Президента України; Стратегія від 25.06.2013 № 344/2013 // База даних «Законодавство України» / Верховна Рада України. URL: https://zakon.rada.gov.ua/go/344/2013 (дата звернення: 30.09.2021).

\section{References}

1. Future shocks: 17 technology predictions for 2025. World Economic Forum. Retrieved from: https://www.weforum.org/agenda/2020/06/17-predictions-for-our-world-in-2025

2. About. Home | National Q-12 Education Partnership | UIUC. Retrieved from: https://q12education.org/about.

3. Key Concepts for Future QIS Learners 5-20. Retrieved https://files.webservices.illinois.edu/9156/keyconceptsforfutureqislearners5-20.pdf.

4. Quantum Technology Competence Framework for QT 1.0. Retrieved from: https://qt.eu/app/uploads/2019/02/Competence_Framework_for_QT_1.0_May2021.pdf

5. Postanova Kabinetu Ministriv Ukrainy [Resolution of the Cabinet of Ministers of Ukraine]. Retrieved from: https://zakon.rada.gov.ua/go/898-2020-\%D0\%BF.

6. Ukaz Prezydenta Ukrainy [Decree of the President of Ukraine]. Pro Natsionalnu stratehiiu rozvytku osvity $v$ Ukraini na period do 2021 roku; Stratehiia vid 25.06.2013 № 344/2013 // Baza danykh «Zakonodavstvo Ukrainy» / Verkhovna Rada Ukrainy. Retrieved from: https://zakon.rada.gov.ua/go/344/2013.

\section{STRUCTURE AND CONTENT OF COMPETENCES ON THE BASICS OF QUANTUM INFORMATICS OF PUPILS FROM LYCEUMS Liudmyla Lehka}

Kryvyi Rih State Pedagogical University, Ukraine

Abstract. The results of the expert survey about identifying the components of competences on the basics of quantum informatics of pupils from lyceums are presented in the article.

Formulation of the problem. The rapid development and promise of quantum technologies in the world are obvious prerequisites of the another transforming of the informatics education content in the Ukrainian general secondary education establishments, as well as clarification of the results of its mastery, there are the components of information and communication (digital) competence. In May 2021, The QTEdu consortium released the first version of the European Competence Framework for Quantum Technologies, components of which are the basis for identifying of the relevant competences for students, in particular full secondary education, as well as for the implementation and realization of educational and scientific projects in the quantum technologies.

Materials and methods. To obtain the results of the study, an empirical method was used (a survey in the form of a semi-open questionnaire, where along with the answer options presented, could be expressed own meaningful comments-recommendations) and a statistical analysis of the results of the survey was done (range to identify the significance of the competencies components).

Results. The conducted expert survey, which was attended mainly by teachers and lecturers, has provided answers and recommendations for the final identification of the content of competencies in quantum informatics of pupils from lyceums: competencies on the physical basics of quantum technologies; competencies on the mathematical foundations of quantum computer science; competencies on enabling technologies; competence in hardware of quantum computers and sensors; competence in quantum computing and modeling; competence in quantum sensors and metrology; competences in quantum communication; practical and soft skills.

Conclusions. The determined structure and content of competencies on the basics of quantum computer science for pupils from lyceums were allowed to clarify the content of the relevant optional course.

Key words: quantum technologies, quantum informatics, competence approach, competences on the basics of quantum informatics.

\section{(cc) BY-NC-SA}

This work is licensed under Creative Commons Attribution-NonCommercial-ShareAlike 4.0 International License. 